\title{
Prospects of digital technologies implementation in the system of human resources management of Russian agricultural companies
}

\author{
Larisa Strelnikova ${ }^{1, *}$ \\ ${ }^{1}$ State Marine Technical University, 3, Lotsmanskaya st., 190008, St. Petersburg, Russia
}

\begin{abstract}
The main trends of the current times are globalization, customer behavior changes and transition to the network digital economy, which define the long term direction of development. The economic and social conditions are transformed in major ways, due to application of digital technologies and this presents the necessity to change key aspects of human resources management in the context of changing companies' business models, especially as it pertains to logistics. In the digital economy, a number of conceptual provisions are being formed that are associated not only with the process of optimization of management in general, but also with the new role of a person, his competencies, their implementation and development based on digital technologies. This study encompasses the results of digital technologies development analysis, as they are applied to human resources management at various Russian companies and organizations. It also presents methodology of project evaluation in the realm of primary digital technologies implementation to education and professional development of logistics companies' personnel. The methodology is based on expert approach, using concordance coefficient and range correlation method.
\end{abstract}

\section{Introduction}

Currently, humanity finds itself on the brink of a new digital revolution wave, the largest in scale so far, and spreading fast, which will significantly modify the global economic system design. Never before has the world been changing as rapidly, as it does today. The internet of things, mobile and cloud technologies, large databases, virtual reality, blockchains and social media move companies to the new level of interaction with their client, change business processes, products and services. Such fast development of IT technologies affects both the competition development and the interaction with clientele meaning that the more information you posses, the faster you can organize service, sales and communication with customers. If previously business strategies were developed for a period of a few years, now six months time frame is considered acceptable [1].

\footnotetext{
*Corresponding author: larochkin@mail.ru
} 
The use of digital technologies brings with it the unprecedented transformation of nearly all fields and introduces changes to our lives, which in the past we could not even imagine. The results of professor L.V. Lapidus' studies of the digital economy evolution testify that current times can be labeled as "digital rush", whereas, starting with 2020 and beyond, it will turn into a "systemic transformation" and quality changes in global economy are highly anticipated [2]. According to Professors E.R. Schislyaeva and E.S. Balashova and E.S Palkina, new digital economy undoubtedly changes all areas in which economic systems are forming and developing - both at macro and micro economic levels. The relevance of modern economic technologies research, as these technologies form its digital and innovation infrastructure, is supported, first of all, by the global economy development trends, its globalization, internationalization of the main processes of the world's national economies, increased competition in the main industrial branches and services [3] .

The application of digital technologies in the modern world is transforming the logistics industry: channels of goods movement, delivery formats and management processes are being optimized. Overall, Russian logistical companies have mastered certain technologies, such as warehouse management system (WMS), Transportation Management System (TMS), online services for clients, etc but their development potential is far from being exhausted [4]. With this in mind, forming and development of the human resource capital of the Russian companies becomes important, as well as the analysis of capabilities and consequences of the digital process application to managing human resources in the conditions of rapid development of innovations.

\section{Materials and Methods}

The scientific foundation of this study is a systemic approach to management of human resources in the conditions of digital economy. An evaluation was conducted of a primary digital technologies application for the corporate education system and personnel's professional development at logistics companies. Range correlation method was used as a forecasting tool, and the level of expert opinions congruence was determined by concordance coefficient.

This study relied on statistical data, scientific conferences materials, workshop data, printed materials, etc that cover modern trends in digital technology applications to economy, as well as in changing human resources management approaches, and vital issues of education methodology development and professional development of logistic companies personnel at the time of global digitalization.

\section{Results}

\subsection{Analysis of digital technologies development level in human resources management of the Russian companies}

Currently five main principles of digital technology use in modern organizations are present [5]:

1. Ultimate centralization. Organization's success in any field of activity is based on unifying people, information and technology in one location, which allows minimizing the quantity of interactions of experts working in key areas or on key projects by analyzing and introducing appropriate instruments.

2. Ultimate automation. Organizations following this approach are heavily engaged in automation process, which allows them to speed up data processing, information transfers 
and lower the possibility of errors by minimizing manual labor, decreasing use of resources, minimizing risks, including those of personnel selection.

3. Ultimate lean and flat organization. This allows an opportunity to minimize the distortion of information being transferred between vertical and horizontal levels, ensuring company's flexibility during implementation of organizational changes and decreasing the number of iterations and cost.

4. Ultimate concentration. This means that organizations using digital technologies, because of their lack of resources, can focus on a limited set of services, but provide them quickly and with high quality, because each of the areas has a team of dedicated specialists working on it.

5. Ultimate simplicity of digital technologies. This approach is based on maximal simplification of internal communication processes, as well as client/partner/supplier interaction activities, which allows relief to the entire system and improves content, as opposed to just improving the company's image.

The determination of the level of digital technology development in human resources management for this study was based on the analysis on online poll among human resources managers of 69 Russian companies and organizations [6].

Respondents fell into the following categories, by field, in manufacturing and non manufacturing Russian companies (see Fig. 1):
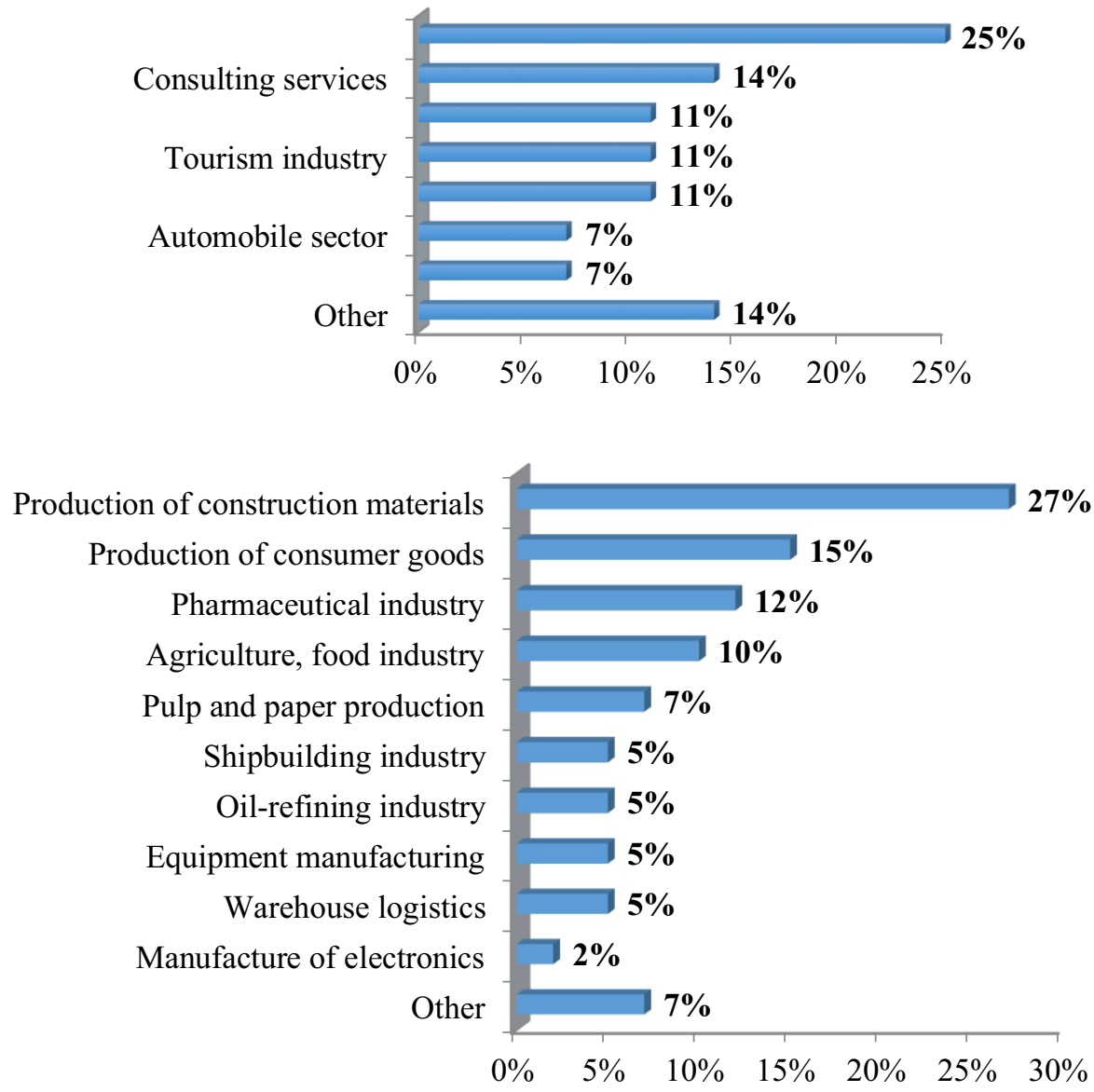
Fig. 1. Distribution of respondents by industry and the field of activity of Russian companies (compiled by the author).

Overall level of digital technology development in human resources management (see Fig. 2) demonstrates that $62 \%$ of respondents partially automated their human resources functionality and plan to continue this process in their companies.

Digital technologies are at the beginning stages of introduction in $15 \%$ of manufacturing companies, and in $21 \%$ of non manufacturing companies. It is of note, that $7 \%$ of manufacturing companies and $12 \%$ of non-manufacturing companies have completed the basic level of digital transformation. On average, $6 \%$ of Russian companies automated certain human resources functionality only, and currently have no plans to continue their development in this direction. Only $7 \%$ of manufacturing companies completed a total digital transformation and automated their entire human resources functionality. Among the non manufacturing companies there are no such examples at all.

The company has gone through a complete digital transformation, automating all the main HR functions

Some HR functions are automated, future development doesn't planned

The company has completed the basic stage of transformation, having automated the main HR functions

The company is at the basic stage of development of digital technologies of HR

Some HR functions are automated, further development is planned

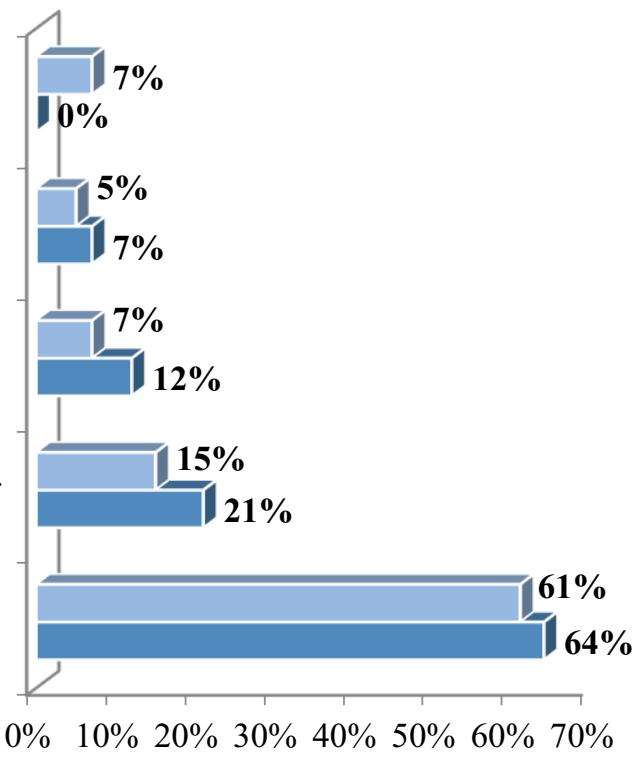

$\square$ Manufacturing companies $\quad$ Non-manufacturing companies

Fig. 2. The level of digital technology development in human resources management (compiled by the author).

Among the human resources functions that were automated by the companies polled, human resources administration is most prominent, with $60 \%$ in non-manufacturing and $89 \%$ in manufacturing companies, accordingly (see Fig. 3). 


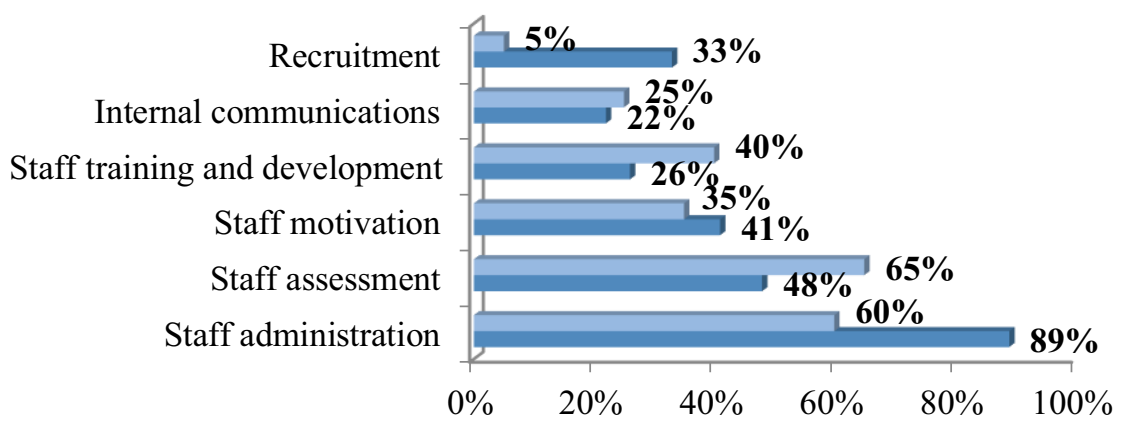

$\square$ Non-manufacturing companies $\quad$ Manufacturing companies

Fig. 3. Distribution of the level of human resources functionality automation in Russian companies (compiled by the author).

As was previously noted above, the automation system has a number of advantages and can significantly simplify the work of human resources managers and specialists. In many Russian companies, automated systems are responsible for electronic documentation - for example, internal personnel tracking, executive orders and memoranda registration, efficient analytical data requests and receipt. Thanks to that, the employees of human resources management departments can perform their jobs, while avoiding errors and optimizing their work appropriately. For example, repetitive entry of the same data into the tracking system becomes unnecessary, risks of penalties from overseeing fiscal organizations are minimized, and documents are filled out correctly, as per the requirements. On average, 55\% of Russian companies automated their function of personnel evaluation. The main purpose of the evaluation and certification is to determine the strengths and weaknesses of employees, to create a human resources reserve pool, to develop individual plans and education requirements for the professional development of the most promising employees. Altogether, these activities increase company's performance effectiveness and its output capabilities. On average, 38\% of respondents automated their systems of payout and benefits, which allowed to create the most optimal social benefits package, taking into account the employees' needs and to increase their level of motivation. As a result, turnover decreases, and loyalty to the organization is on the rise. $32 \%$ of respondents conducted the personnel development and education process automation, of those $65 \%$ are non manufacturing companies. As was mentioned above, individual and group education programs for companies' personnel are developed on the basis of personnel evaluations, including the results analysis. On average, $23 \%$ of companies automated their internal communications. Companies' leadership attempts to bring more harmony to the employees' collaboration, including while building processes for remote work. Fast and convenient is communication through messenger systems, IP phones, and conference calls. Also introduced are company platforms/sites, where company news, colleagues information, contact information, etc can be easily found, and communication between individual employees can be established. $21 \%$ of companies automated their function of personnel selection; however, only $5 \%$ of respondents belong to non-manufacturing organizations. Often times, recruiters and human resources managers create their databases using Excel, which then requires massive time periods for information analysis and transfer of notes and comments from paper to the electronic format. Personnel selection automation allows minimizing routine operations and free time for search and selection of candidates for available vacancies. 
According to the respondents, digitalization processes and the deficit of qualified workforce are main factors influencing the labor market, and specifically affecting its future development (see Fig. 4). Approximately one third of the respondents believe that generational issues will be predominant in human resources management field and a quarter of companies chose the demographics.

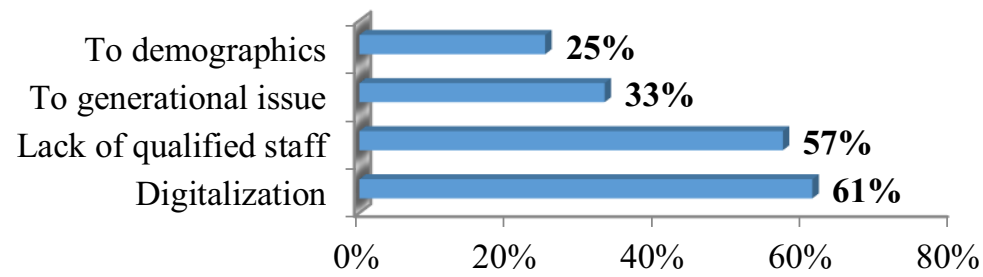

Fig. 4. Factors expected to affect the human resources management in the next few years (compiled by the author).

Therefore, the digitalization market share in human resources management field not only is expected to grow, but it is expected to dictate the direction of the entire field development, in the next few years. According to the data from the Grand View Research Agency, the world market of technical innovation in HR field reached $\$ 14 \mathrm{~B}$ and, according to the forecasts, by 2025 it will reach $\$ 30 \mathrm{~B}$ [7].

Russian experts opine that the priority directions in the human resources management in the next two years will be as follows (see Fig. 5):

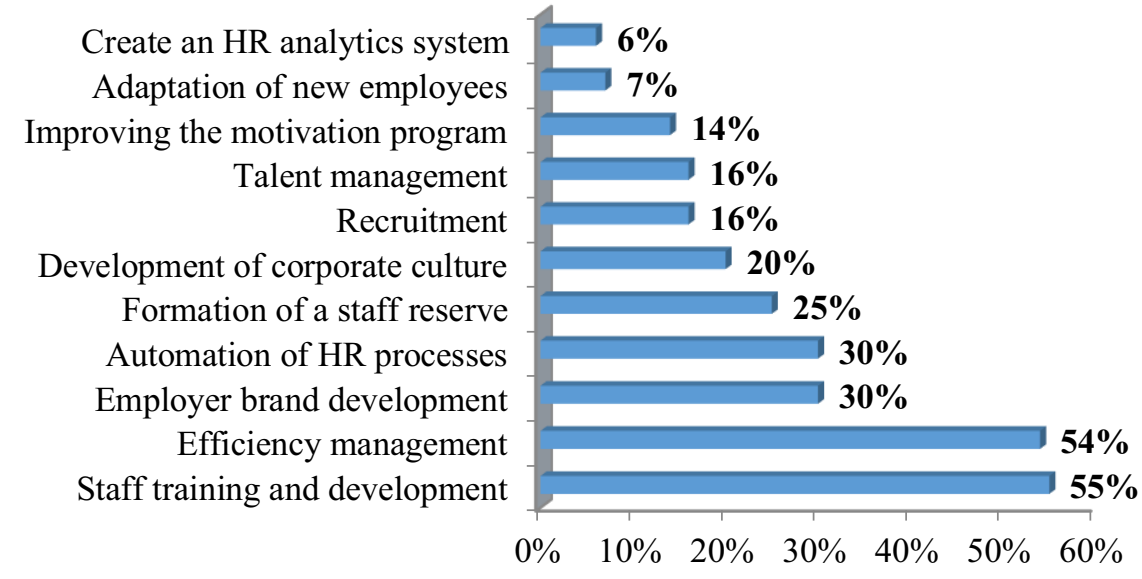

Fig. 5. Priority directions for human resources functionality in the near future (compiled by the author).

Analysis demonstrates that in the world and Russian experience, the human factor gains paramount importance. Currently, while "Industry 4.0" is getting established, employees, with their knowledge and skills, are the key strategic resources of companies in any field. It is their intellectual potential and experience that allows organizations to develop and assume leadership positions in the market. In the new economy, heavily engaged in digitalization, abovementioned factors eventually lead to understanding and transformation of the applied technologies and practices in the human resources management. As shown in Figure 5 diagram, the main direction in human resources management is creation of the education and professional development system, based on the introduction of digital 
technologies. The vitality of digital learning prospects in Russian companies, especially in logistics, first of all, is paired with the use of most optimal and economically viable methods of knowledge generation and transfer, in accordance and congruence with the current technological and social transformations.

\subsection{Brief analysis of capabilities and scenarios of digital technology application in the process of educating the logistic companies' employees}

Currently in Russia, the following digital education systems and resources are present and utilized: Competentum resource, Naumen solution, Web Tutor System, eLearningServer, RedClass Complex. Among the foreign-made ones are: LearneXact resource, promoted by the Content Design Center of the Moscow State University of Economics, Statistics and Computer Science, Bitmedia's Sitos system, IBM Lotus workplace Collaborative Learning, remote education system E-learning now, in person education system ManageNow, NETg and Skillsoft libraries, which contain a large volume of materials for a variety of electronic, online courses.

Below are the examples of digital technology implementation in Russian logistic companies, confirming that the organizational process of the electronic education can be fairly engaging and help develop necessary professional skills [9]:

1. Practicing employee skills. To educate employees of logistic companies, a Dialogue Training Module is often used. It helps memorize a scenario of optimal behavior even in the most stressful situation - for example, during a conflict with a client. Not too long ago, Speech Modules became available, and they analyze not only the content of the response, but the tone and intonations of the speaker. In particular, the Drag-and-Drop Module was applied by the LeaderTeam Company specializing in outsourcing of sales and logistics. The company employs a significant number of people, and often those with little to no experience end up being Merchandisers. The simulator trains employees to correctly shelve merchandise in a game format. Such interactive modules and applications help to form the first useful and positive experience, while learning the basics of the profession. Program Development Modules are especially well suited for training apprentices, because corporate software does not always have a simple interface. For example, Major Cargo Service Company, some new employees had difficulties in understanding the complicated interface of the client management program (CRM). This resulted in errors and financial losses for the company. Using training modules allowed to significantly speed up the process of new employees adaptation, due to better understanding of how the system operates.

2. Adaptive knowledge management. Many Russian logistics companies implement a Web Tutor Module, as their knowledge management system. It determines the level of personnel competency and creates an individual education program, based on the existing learning materials. Soft Skills and flexible skills development is the development of non specialized skills, that are not directly part of the employee's job description, such as team building, time management, leadership, etc. SpetsTransGroup Company provided electronic Competentum Course, in order to teach personnel business etiquette and train employees to manage stress and make decisions quickly, as well as manages logistics flow and achieves their timely completion.

3. Quick competency testing after completion of the education course. DHL across Russia automated personnel certification by introducing cloud technologies for efficient knowledge and skill testing of its customer service departments. Employees can take tests, using any mobile device at any convenient time. It is demonstrated that company's regional offices, where specialists regularly participate in continuing education and achieve good testing results, profits also increase. 
4. There are also Russian companies specializing in development of electronic education courses, including trainings, videos, tests, presentations, which are later stored in the unified training database: Training Media Company, E-Learning Ceter, CSSeTrain Company, New Disk Company, Training Soft Resource, OKS Company.

\subsection{Methods of Evaluation of the Project for Primary Digital Technologies Introduction into the corporate education and personnel development system of the logistics companies}

The project focused on the two of the six identified possible priority events and took into account the specifics of workload of the certain staff members of one of Russia's logistics companies:

1. Training by using the gaming tools and modules.

2. Using cloud solutions in creation of the online course.

3. Using the dialogue module for practicing behavioral skills.

4. Using modules for learning computer software skills.

5. Knowledge management system implementation.

6. Post educational employee certification process automation.

In order to determine the priority in the sequence of events, it is necessary to analyze their significance. To evaluate the expert opinion congruence as to the significance of each event, a concordance coefficient (W) is determined as follows (Formula 1):

$$
W=\frac{12 \sum_{j=1}^{m} d_{j}^{2}}{n^{2}\left(m^{3}-m\right)}
$$

where: $n$-number of experts; $m$ - quantity of parameters (directions, objects evaluated); $d_{j}^{2}$ - squared, deviation of the sum of ranges in $j$ direction, from the range average.

When assessing the importance of events, given equal ranges, among all selected by the expert, the congruence of expert evaluations is determined as follows (Formula 2):

$$
W=\frac{12 \sum_{j=1}^{m} d_{j}^{2}}{n^{2}\left(m^{3}-m\right)-n \sum_{i=1}^{n} T_{i}}
$$

where: $T_{\mathrm{i}}$ - indicator of equal ranges.

Expert Evaluation Results are presented in Table 1, where the first column indicates the sequence number of the abovementioned possible events, the second column is for expert evaluations of their significance for the company, by determining the congruence coefficient.

\begin{tabular}{|c|c|c|c|c|c|c|c|c|c|}
\hline \multirow[t]{2}{*}{ Events } & \multicolumn{3}{|c|}{$\begin{array}{l}\text { Expert Evaluation of } \\
\text { the event significance } \\
\text { (weighting factor) }\end{array}$} & \multicolumn{3}{|c|}{$\begin{array}{c}\text { Expert Evaluation of } \\
\text { the event significance } \\
\text { (ranges) }\end{array}$} & \multirow{2}{*}{$\begin{array}{c}\text { Sum of } \\
\text { Ranges, } \\
S_{j}\end{array}$} & \multirow[t]{2}{*}{$1 / S_{j}$} & \multirow{2}{*}{$\begin{array}{l}\text { Squared, the } \\
\text { deviation of } \\
\text { the sum of } \\
\text { ranges, } d_{j}^{2}\end{array}$} \\
\hline & 1 & 2 & 3 & 1 & 2 & 3 & & & \\
\hline 1 & \multicolumn{3}{|c|}{2} & \multicolumn{3}{|c|}{3} & 4 & 5 & 6 \\
\hline 1 & 0.1 & 0.2 & 0.1 & 5 & 2.5 & 4.5 & 12 & 0.08 & 2.25 \\
\hline 2 & 0.1 & 0.2 & 0.3 & 5 & 2.5 & 1.5 & 9 & 0.11 & 2.25 \\
\hline 3 & 0.1 & 0.1 & 0.1 & 5 & 5.5 & 4.5 & 15 & 0.06 & 20.25 \\
\hline 4 & 0.2 & 0.2 & 0.1 & 2.5 & 2.5 & 4.5 & 9.5 & 0.10 & 1 \\
\hline 5 & 0.3 & 0.2 & 0.1 & 1 & 2.5 & 4.5 & 8 & 0.12 & 6.25 \\
\hline 6 & 0.2 & 0.1 & 0.3 & 2.5 & 5.5 & 1.5 & 9.5 & 0.10 & 1 \\
\hline Total & 1 & 1 & 1 & - & - & - & 63 & 0.57 & 33 \\
\hline
\end{tabular}

Table 1. Evaluation of congruence of expert opinions. 
Also, the experts ranged the assessments of the importance of activities. Each evaluation given by the $i$-th expert is expressed by the number of natural scale - the range $R_{\mathrm{ij}}$ - in such a way that the maximum grade is assigned the value 1 , and the minimum $-n$. In case of the expert evaluations are equal, they will be included in the same range, equal to the arithmetical mean of the corresponding numbers of the natural scale.

The calculation of the sum of ranges in every direction $S_{j}$ is implemented according to Formula 3:

$$
S_{j}=\sum_{i=1}^{n} R_{i j}
$$

In the fourth and fifth columns of Table 1 the results are presented of calculating the sum of ranges and reciprocal $1 / S_{j}$.

Calculation of the average for the sum of ranges in all directions is implemented according to Formula 4:

$$
\bar{S}=\frac{\sum_{j=1}^{m} s_{j}}{m}
$$

where: $m$ - quantity of directions being evaluated; $i$ - the number of the direction.

In our case the average of the sum of ranges is: $S=63 / 6=10.5$.

Calculation of deviation of the sum of ranges in direction $j$ from the average of the sum of ranges is done using Formula 5:

$$
\begin{gathered}
d_{j}=S_{j}-\bar{S} \\
d_{1}=12-10.5=1.5 ; \\
d_{2}=9-10.5=-1.5 ; \\
d_{3}=15-10.5=4.5 ; \\
d_{4}=9.5-10.5=-1 ; \\
d_{5}=8-10.5=-2.5 ; \\
d_{6}=9.5-10.5=-1
\end{gathered}
$$

The results of calculating the squared deviation of the sum of ranges $d_{j}^{2}$ are put in the last column of Table 1.

The calculation of the indicator characterizing equal ranges is implemented according to the Formula 6:

$$
T_{i}=\sum\left(t_{i}^{3}-t_{i}\right)
$$

where: $\mathrm{t}$ - quantity of equal ranges in group $i$.

In our case:

$$
\begin{gathered}
T_{1}=\left(3^{3}-3\right)+\left(2^{3}-2\right)=30 \\
T_{2}=\left(4^{3}-4\right)+\left(2^{3}-2\right)=66 \\
T_{3}=\left(4^{3}-4\right)+\left(2^{3}-2\right)=66 \\
\sum_{i=1}^{n} T_{i}=162
\end{gathered}
$$

Further follows the calculation of the concordance coefficient. In this example, there are equal ranges, and they are presented by the same expert. Therefore, the concordance coefficient is calculated according to the Formula 2: 


$$
W=12 * 198 /\left[3^{2}\left(6^{3}-6\right)-3 * 162\right]=1.69 .
$$

As a rule, when the congruence of expert opinions is insufficient, the concordance coefficient is less than 0.75 . In our particular case it is 1.69 and therefore an additional study is not required.

An analysis of the significance of the parameters being studied was also conducted. An average weight factor is determined as a reciprocal of the sum of ranges as it relates to their sum (Formula 7):

$$
\overline{K_{\text {weight }}}=\frac{1 / s_{j}}{\Sigma^{1} / s_{j}}
$$

After necessary calculations the following results were compiled:

$$
\begin{aligned}
& K_{\text {weight } 1}=0.08 / 0.57=0.14 ; \\
& K_{\text {weight } 2}=0.11 / 0.57=0.19 ; \\
& K_{\text {weight } 3}=0.06 / 0.57=0.10 ; \\
& K_{\text {weight } t}=0.10 / 0.57=0.18 ; \\
& K_{\text {weight } 5}=0.12 / 0.57=0.21 ; \\
& K_{\text {weight }}=0.10 / 0.57=0.18
\end{aligned}
$$

Thus, in the opinion of the expert group, the most effective measure in the framework of the project for the introduction of digital technologies into the corporate training system of Logistics Company being studied is the use of software simulators by trainees $-21 \%$. Experts also considered trainings using the gaming module fairly effective - at $19 \%$. Equally effective, at $18 \%$, will the following two events: use of the dialogue simulator for practicing behavioral skills and automation of employee certification process after completion of the educational course. Less effective in the opinion of the experts are application of cloud solutions to creating an online course and introduction of the system of knowledge management.

It is important to note that employee education process that integrates digital technologies with the human resources management strategy becomes the most important instrument in intellectual capital development at Russian logistics companies, as well as a key requirement for successfully achieving their strategic goals and increasing competitiveness by transforming their business from a traditional to a technology savvy company

\section{Discussion}

The analysis allows identifying the main positive aspects of the introduction of digital technologies in the field of human resource management:

1. Automation and optimization of work processes leads to savings in the time resources of HR specialists and the cost of implementing personnel activities

2. Digitalization allows to excluding the human factor in the implementation of many operations, since programs, applications and services always comply with clear standards, rarely give failures and mistakes, aren't subject to fatigue, and their performance doesn't dependent on many factors, as is the case with a humans.

However, digitalization of HR processes hasn't only advantages and benefits, but also have contains certain disadvantages and risks:

1. The relatively high cost of implementing digital technologies. 
2. The risk of job cutting requiring medium and low qualifications because of the complete automation of labor processes.

3. High cost of mistakes. Unfortunately, there no system is immune to make errors, and even innovative technologies can malfunction.

Business digitalization actively affects the functionality of HR managers, over by organizational tasks and processes have been automated, and therefore more developed competencies in the field of digital technologies are required from staff. Human resources service in companies today is no longer just a performer, but a kind of business partner who provides services for providing business with qualified staff and their development. Therefore, in order to maintain the work of HR departments need to minimize risks at all stages of selection, professional development and motivation of company employees, have to build effective interaction, new methods and technologies, including digital.

\section{Conclusions}

With the high development of digital technology, companies need to have been flexible and constantly adapt to new trends. The analysis have shows there in the context of the innovative stage of development of the modern economy have wide selection of digital solutions that opens up completely new opportunities for HR specialists for the rational using of human and financial resources. Using of digital technologies creates the preconditions for a multiple increase in the performance of HR departments, also ensured technologically competent implementation of management activities and the effective functioning of organizations in general.

\section{References}

1. N. Zagrebelnaya, E. Bostoganashvili, Economics: yesterday, today, tomorrow 9(1A), 374-384 (2019)

2. L. Lapidus, Second International Conference - Business Management in Digital Economy St. Petersburg, 72-75 (2019)

3. E. Balashova, E. Palkina, E. Schislyaeva, International Conference on Digital Transformation in Logistics and Infrastructure (ICDTLI 2019). Atlantis Highlights in Computer Sciences St. Petersburg 1, 80-85 (2019)

4. N. Dmitriev, O. Smirnova, Digest: Digital economy and industry 4.0: Foresight Russia. Digest of articles from scientific workshop with participants from abroad (St. Petersburg Politechnical University named after Peter the Great, 2020)

5. E. Balashova, E. Schislyaeva, A. Bogomolov, An Audit and financial analysis 4, 193196 (2019)

6. L. Strelnikova, Human Resources Management Digitalization. Applicable technologies of the modern economy and infrastructure: digital and innovative economics (Publishing House of the St. Petersburg State Marine Technical University St. Petersburg, 2020)

7. A. Kozlov, A. Kankovskaya, A. Teslya, IOP Conference Series: Materials Science and Engineering 1 (2019)

8. K. Plis, International Scientific Conference Global Challenges of Digital Transformation of Markets (GDTM 2020) (St. Petersburg, 2020) 
9. V. Vasilenok, A. Kruglova, E. Aleksashkina, V. Negreeva, S. Plastunova, Scientific Journal of the National Research University of Computer Science, Mechanics and Optics, Series: economics, sustainable management 1, 69-78 (2020)

10. E. Balashova, E. Gromova, Revista Espacios 38(53), 31-36 (2017)

11. E. Balashova, I. Krasovskaya, E. Schislyaeva, F. Shamrai, International Scientific Conference: Digital Transformation on Manufacturing, Infrastructure and Service (DTMIS-2019) (St. Petersburg, 2019)

12. E. Balashova, O. Saychenko, S. Sharipova, E. Schislyaeva, Advances in Intelligent Systems and Computing Springer Nature Switzerland AG, 131-138 (2020)

13. A. Dubgorn, M. Abdelwahab, A. Borremans, I. Zaychenko, Proceedings of the 33rd International Business Information Management Association Conference (IBIMA 2019), 9677-9682 (2019)

14. E. Palkina, Materials of the Russian National scientific conference, Federal Agency of Transportation Issues named after Solomenko N.S, of the Russian Academy of Sciences, 198-202 (2018)

15. E. Palkina, International Conference on Modern Trends in Manufacturing Technologies and Equipment (ICMTMTE 2018) St. Petersburg 224 (2018)

16. K. Plis, O. Kalchenko, S. Evseeva, O. Evseeva, 1th International Scientific and Practical Conference on Digital Economics (ISCDE 2019) St. Petersburg (2019)

17. C. Soo, A. Tian, S. Teo, J. Cordery, Human Resource Management 56(3), 431-454 (2017)

18. E. Schislyaeva, S. Barykin, S. Schislyaev, E. Kovalenko, International Conference on Digital Transformation in Logistics and Infrastructure (ICDTLI 2019) 1, 185 - 192 (2019)

19. E. Schislyaeva, A. Saychenko, International research and practice conference Munich, Germany I, 343-351 (2014)

20. B.P. Von Ohain, 40th International Conference on Information Systems (ICIS 2019) Munich, Germany 40 (2019) 